\section{Dr. Braun-Moscovici, et al reply}

\section{To the Editor:}

We thank Dr. Calzolari, et al for the comments on our article ${ }^{1}$. We were interested to learn that the Italian team found similar results of hypovitaminosis D in a Mediterranean population of patients with scleroderma. As mentioned, several factors may influence vitamin D status in scleroderma patients, including malabsorption secondary to gastrointestinal involvement, low exposure to sun, and the possible correlation between inflammatory disease and vitamin D levels. Dr. Calzolari suggested the effect of skin thickening on vitamin D synthesis. In our study, we found low vitamin D levels in $46 \%$ of patients, most with very limited skin disease. Several studies showed an abnormal pattern of fibroblasts, vascular endothelial growth factor (VEGF) proteins, and abnormal biomechanical skin properties in clinically normal skin of patients with limited scleroderma ${ }^{2,3}$. To our knowledge, there are no studies of vitamin D metabolism in the skin of patients with scleroderma (limited or diffuse) and indeed, this is an issue for further research.

Radiographic imaging is more sensitive than physical examination in revealing calcinosis and acroosteolysis. This might explain the high prevalence of acroosteolysis in our patients and in other studies. Most of the patients with scleroderma followed in our department are treated with calcium blockers and intravenous iloprost. We found no correlation between prevalence of acroosteolysis or calcinosis with therapy. We did find correlation with disease duration and with parathyroid hormone levels.
Prolonged exposure to low vitamin D and/or to tissue hypoxia might explain the correlation with disease duration.

We agree with Dr. Calzolari that there is a need for further research regarding the effect of vitamin D on disease progression, and on bone and immune metabolism in scleroderma.

YOLANDA BRAUN-MOSCOVICI, MD, Rambam Health Care Campus, Rheumatology, POB 9602, Haifa, 31096, Israel; DANIEL E. FURST, MD, UCLA Medical School, Los Angeles, California, USA; MENACHEM A. NAHIR, MD; ALEXANDRA BALBIR-GURMAN, MD, Rambam Health Care Campus, Rheumatology. Address correspondence to Dr. Braun-Moscovici; E-mail: yolanda_bm2001@yahoo.com

\section{REFERENCES}

1. Braun-Moscovici Y, Furst DE, Markovits D, Rozin A, Clements PJ, Nahir AM, et al. Vitamin D, parathyroid hormone and acroosteolysis in systemic sclerosis. J Rheumatol 2008;35:2201-5.

2. Davies CA, Jeziorska M, Freemont AJ, Herrick AL. The differential expression of VEGF, VEGFR-2, and GLUT-1 proteins in disease subtypes of systemic sclerosis. Hum Pathol 2006;37:190-7.

3. Balbir-Gurman A, Denton CP, Nichols B, Knight CJ, Nahir AM, Martin G, et al. Non-invasive measurement of biomechanical skin properties in systemic sclerosis. Ann Rheum Dis 2002;61:237-41.

J Rheumatol 2009;36:12; doi:10.3899/jrheum.090703 